\title{
Consent ain't anything: dissent, access and the conditions for consent
}

Ezio Di Nucci (University of Copenhagen)

\begin{abstract}
I argue against various versions of the 'attitude' view of consent and of the 'action' view of consent: I show that neither an attitude nor an action is either necessary or sufficient for consent. I then put forward a different view of consent based on the idea that, given a legitimate epistemic context, absence of dissent is sufficient for consent: what is crucial is having access to dissent. In the latter part of the paper I illustrate my view of consent by applying it to the case of consenting to being an organ donor.
\end{abstract}

\section{Introduction: What is Consent?}

I argue that consent is neither an attitude nor an action. In fact, consent isn't anything: absence of dissent (under legitimate epistemic conditions) is all there is to it. More important than what consent is, anyway, should be the question of what consent can (do), because consent is very powerful: its presence or absence can be decisive for the legitimacy of an event or state of affairs. This capacity has also been called moral transformation: consent makes it "permissible for $A$ to act with respect to $B$ in a way that would be impermissible absent valid consent" (Miller \& Wertheimer 2010: 79). ${ }^{1}$

The question is: what are the necessary and sufficient conditions for such moral transformation? This is just another way of asking what consent is. ${ }^{2}$ It should be said early on - on the other hand - that consent is not always transformational but only in particular sets of circumstances, which we could summarize by saying that they all have to do with a loose sense of ownership. Consent is normally taken to be decisive when it comes, for example, to

\footnotetext{
${ }^{1}$ See also Beyleveld \& Brownsword 2007.

${ }^{2}$ By this statement I also mean that my arguments here are not concerned with the legitimacy of language uses around the term 'consent' but only with the normative powers of this concept. It could also be, on the one hand, that folk should use the term 'consent' under the conditions established by my argument - but I am not interested in this claim. Further, it could also be that, as a matter of fact, folk already do only use the term 'consent' under the conditions established by my argument - but this empirical issue is beyond the scope here.
} 
the human body or its parts, on the assumption that we own our body in a morally relevant sense; something similar goes for property. Consent has also been thought to be relevant when it comes to autonomy and individual liberty: the idea being that the relinquishment of our liberties (to the state, for example) can only be legitimized, if at all, by consent.

Also, consent appears to have transformational powers when it comes to hierarchical relations of authority, within families, businesses or institutions - but also to equal relationships such as between romantic or business partners. Here I neither want to offer a comprehensive list nor do I want to get into the details of the similarities between these different applications of consent: these preliminary remarks are just meant to clarify that consent's powers of transformation are not unlimited. I my tell pedestrians walking past my flat that I approve of their walking past, but that does not make any difference to the legitimacy of their walking past as they have a right to do so which is independent of me. Similarly, my duties towards my children are independent of consent.

Let us start our analysis of consent by looking at Thomas Hobbes's classic distinction:

Signs of contract are either express or by inference. Express are words spoken with understanding of what they signify: and such words are either of the time present or past; as, I give, I grant, I have given, I have granted, I will that this be yours: or of the future; as, I will give, I will grant, which words of the future are called promise.

Signs by inference are sometimes the consequence of words; sometimes the consequence of silence; sometimes the consequence of actions; sometimes the consequence of forbearing an action: and generally a sign by inference, of any contract, is whatsoever sufficiently argues the will of the contractor. (Hobbes, Leviathan, Ch. 14)

These passages from the Leviathan have been normally taken to be early attempts at determining consent's conditions of satisfaction, at least for what concerns political 
obligation and obedience to the law in contractualist political philosophy. ${ }^{3}$ Hobbes distinguishes between 'express' signs of contract and 'by inference' signs of contract; the former would be, for example, the kind of explicit verbal agreement involved in exchanging marriage vows. This may indeed be taken to be the simplest form of consent: both parties are present, simultaneously; both parties express their consent verbally and are in an ideal position to receive the other's consent, as they normally sit or stand next to each other.

On the other hand, it is easy to show that such direct verbal context can be neither necessary nor sufficient for consent. It is not necessary, Hobbes goes on to argue, because consent does not need to be 'express'; it can also be 'by inference'. But, as our patriarchal history shows, the direct verbal context of marriage vows does not guarantee consent either, as countless brides (and even some grooms) have been forced by violence, threats or other illegitimate means to express verbal agreement: so direct verbal agreement is neither necessary nor sufficient for consent.

John Locke is another classic source on consent. Differently from Hobbes, Locke formulates things explicitly in terms of 'consent' and in terms of its 'sufficient' conditions:

Every man being, as has been shewed, naturally free, and nothing being able to put him into subjection to any earthly power, but only his own consent; it is to be considered, what shall be understood to be a sufficient declaration of a man's consent, to make him subject to the laws of any government. There is a common distinction of an express and a tacit consent, which will concern our present case. No body doubts but an express consent, of any man entering into any society, makes him a perfect member of that society, a subject of that government. The difficulty is, what ought to be looked upon as a tacit consent, and how far it binds, i.e. how far any one shall be looked on to have consented, and thereby

\footnotetext{
${ }^{3}$ Here I am, in the first place, only interested in the concept of consent and its normative powers and not in its application to the justification of political obligation - the latter debate is beyond the scope here. I say "in the first place" because there is, on the other hand, at least one outcome of the argument I present here that I will not rule out at the outset: if one were to think that a consent-based justification of political obligation is implausible on the grounds that Locke's conditions are too permissive, then my argument here may be relevant to those particular reasons for rejecting a consent-based justification of political obligation.
} 
submitted to any government, where he has made no expressions of it at all. And to this I say, that every man, that hath any possessions, or enjoyment, of any part of the dominions of any government, doth thereby give his tacit consent, and is as far forth obliged to obedience to the laws of that government, during such enjoyment, as any one under it; whether this his possession be of land, to him and his heirs for ever, or a lodging only for a week; or whether it be barely travelling freely on the highway; and in effect, it reaches as far as the very being of any one within the territories of that government. (Locke, Second Treatise of Government, Sec. 119)

Locke's conditions - taking the mere presence of someone in the territory of the state to be sufficient for consent - have been taken to be too weak, at least in the context of contractualist political obligation. Simmons' critique has been particularly influential in recent decades:

I may give my consent by any number of means. Words, gestures, and lack of response are all suitable methods in appropriate contexts... I wish to emphasize only two general conditions, which will figure in later discussion. First, consent must be given intentionally and (perhaps this is redundant) knowingly; as with promising, one can consent insincerely, but not unintentionally. Second, consent must be given voluntarily. It is not possible to be precise about this condition, but there are at least obvious cases on either side of a fuzzy line; "consent" which is given under the direct threat of serious physical violence is, for instance, not really consent according to this condition. (Simmons 1976: 276-277)

Notice that Simmons is also concerned with the sufficiency rather than the necessity of Locke's account of consent: Simmons stipulates, on the one hand, that genuine consent needs to be both intentional and voluntary; but he allows, on the other hand, that consent can be tacit: "I have already suggested that tacit consent should not be taken by the consent 
theorist to be an "unexpressed" consent; calling consent tacit on my account specifies its mode of expression, not its lack of expression." (Simmons 1976: 282)

So far we seem to have established that verbal or propositional agreement (spoken or written, say) is neither necessary nor sufficient for consent: it is not necessary for the simple reason that one does not need to say or write anything in order to consent; and it is not sufficient for the similarly simple reason that one may not say or write what one meant to say or write (this would be Simmons' intentionality condition); also, one may not say or write what one would actually like to say or write (this would be Simmons' voluntariness condition).

Certain cases need including within the concept of consent, namely those cases where someone consents without saying or writing anything. Here is a classic case from Simmons:

Consider: Chairman Jones stands at the close of the company's board meeting and announces, "There will be a meeting of the board at which attendance will be mandatory next Tuesday at 8:00, rather than at our usual Thursday time. Any objections?" The board members remain silent. In remaining silent and inactive, they have all tacitly consented to the chairman's proposal to make a schedule change (assuming, of course, that none of the members is asleep or has failed to hear). As a result, they have given the chairman the right (which he does not normally have) to reschedule the meeting, and they have undertaken the obligation to attend at the new time. (Simmons 1976: 278-279)

Certain other cases need ruling out even though they may appear to be cases of consent, such as the already mentioned patriarchal case of the bride being forced or threatened into marriage. Now the following two questions must be answered:

(a) What do the former cases have in common with genuine consent so as to justify inclusion? 
(b) And how do the latter cases differ from genuine consent so as to justify exclusion despite appearances?

One may answer to (a) that the former kinds of cases need to be included because board members do in fact agree even though they do not voice their agreement: so the board members' attitude is one of agreement and that should be enough for inclusion, given the circumstances. Similarly, one may answer to (b) that the unwilling bride does not in fact agree even though she appears to do so: so the bride's attitude is not one of agreement and that should be enough for exclusion.

\section{Is Consent an Attitude?}

These answers raise the question of whether consent is an attitude (mental or otherwise). Onora O 'Neill, for example, has argued that consent is a propositional attitude:

\footnotetext{
A reasonable starting point is to note that consent is a propositional attitude, given in the first instance not to another's action, but to a proposition describing the action to be performed (other propositional attitudes include knowing, desiring, hoping, expecting, believing). ( $\mathrm{O}^{\prime} \mathrm{Neill}$ 2003: 5)
}

Is an attitude of agreement or approval necessary for consent? Is an attitude of agreement or approval sufficient for consent? One may think that a psychological attitude of agreement or approval (for present purposes I shall just stipulate no attitudinal difference between 'agreement' and 'approval' - the same goes for 'willingness', which is another term often used in the literature) should be both necessary and sufficient for consent: it is necessary, this proposal would go, because if the agent does not actually approve of the relevant event or state of affairs, then no behaviour that may apparently resemble approval should qualify as consent: so that the bride who is forced to the altar through violent threats does not consent even though she may say things like 'I do', 'I will' or 'Yes' - and the view of consent according to which an attitude of approval is necessary for consent can explain why the unwilling bride does not actually consent even though it looks as though she would: she 
does not actually consent because she lacks the relevant psychological attitude of approval (whatever form that may actually take within our psychology).

What about the claim that an attitude of approval should be sufficient for consent? Here this view has something interesting to say too. Take the following common situation: someone is delivered to the emergency rooms in a critical condition. Her state is such that she cannot give her consent to surgery while at the same time she will very likely die or suffer serious permanent injuries without immediate surgery; add that no relative is at hand either, and you have a situation where if the hospital cannot somehow assume consent on the part of the patient, the patient will suffer because of it.

Here the view that consent is a psychological attitude of approval has something useful to offer: in most cases we will have good reason to conclude that the patient does indeed have the relevant attitude of approval even though she cannot express it at this very moment in time because of her critical condition; but since the view that consent is a psychological attitude of approval holds that the attitude is not only necessary but also sufficient, here the hospital does not need the patient to be able to express her attitude; it is enough that the agent has the relevant attitude; and if we have good reason to believe that the patient does have the relevant attitude, then the hospital can proceed irrespective of the patient current's inability to express her attitude of approval. ${ }^{4}$

There is nothing incoherent with the claim that a psychological attitude of approval is sufficient for consent. But remember what we said at the beginning about what consent can do being more important than what consent is: consent is a powerful tool; but it will lose its powers of transformation if we accept that a psychological attitude of approval is sufficient, simply because such a view of consent would be epistemically unworkable. It would be as if we said that what counted for the formation of a new government - what would have the power of transformation over government - would be what citizens approved of rather than what they voted for. It may be coherent to stipulate that some government has the majority

\footnotetext{
${ }^{4}$ Note that the suggestion does not depend on being able to argue that the patient is only temporarily unable to express the relevant attitude; if possession of the relevant attitude is sufficient, then the hospital can proceed even if the patient were to be permanently incapacitated to express the relevant attitude as long as there was good reason to believe that the patient possessed the relevant attitude.
} 
in Parliament if and only if the majority of citizens approve of that government, but such a democracy would be unworkable. Approving of a politician or political party is not enough: it is not sufficient, in democratic systems, to put them in power. You (and a whole lot of other people) also need to vote for them. Similarly, approving of some event or state of affairs is also not sufficient: you also need to consent to it. This political analogy also suggests another problem with the attitude view: a person's approval may be the result of manipulation by someone else, and in these cases it would be at least problematic to take such manipulated approval to be sufficient or even just relevant for consent.

As we now move to discuss the necessity of a psychological attitude, we will see that the above is not my only argument against the sufficiency of an attitude - at least one of my arguments against the necessity of the attitude is also an argument against its sufficiency. Can we be said to consent to an event or state of affairs failing an attitude of approval towards said event or state of affairs? I think we can, as the examples below show.

1) We are often indifferent to things that happen around us: we just have no attitude (positive or negative) towards them but are happy enough to let these things happen even when stopping them or preventing them would not cost us much if anything at all. Your bank, insurance, phone company, email provider, social network change their terms of use often on a monthly basis: when was the last time that you did something about it? When was the last time that you even read what the changes were? These are cases where changes occur which are from our perspective minor enough so that they do not deserve any prolonged attention: we may notice the relevant change (many of the companies in our examples are bound by contract to inform us) but never give it any thought: mostly, we never get around to form any attitude negative or positive about it; we are just indifferent (and certainly one could take indifference itself to be an attitude, one which is neither positive nor negative but still an attitude, say a non-negative attitude; but as we argue later on indifference must not be necessarily conceived as an attitude). This, mind, should not be taken to be a form of irrationality: irrational may very well be, on the other hand, to spend one's free time by reading all the different terms of use of all the different service providers 
with which we interact on a daily basis. Indeed, in that case reading their terms of use may end up being the only kind of interaction that we would have time for.

2) Indifference is not the only kind of case where we lack a positive attitude of approval. Modern societies are increasingly built on division of labour and epistemic authority. We are very often ignorant of facts that are relevant to our interests, well-being, or future: things have just got too complicated for us to keep up with everything which directly influences our lives, so we specialize and trust that others will do likewise and that we will be able to rely on their specialty when necessary. Sometimes the situation is delicate enough so that we are obliged to sign an informed consent form, as before surgery, which tells us in some details what risks this particular procedure involves. But in more informal settings we normally just rely on the professionalism of others: we can't approve of what the plumber does to our boiler just because we have no idea of what they are doing, nor do we normally ask the plumber at the door for proof of identity; we vaguely approve of this guy trying to fix our boiler and trust that this is what the plumber is trying to do. Again, just like with indifference, this ignorance should not be taken to be irrational: it is rather the normal consequence of division of labour; most of us never wanted to be plumbers and are perfectly happy not to know how to repair boilers.

Cases of ignorance could be also analysed as follows: we cannot consent to what the plumber is going to do because we have no idea what the plumber is going to do but we still authorize the plumber to do whatever the plumber is going to do: the idea being that we are ignorant about what is wrong with our boiler but we are not ignorant about our preference towards the boiler working again, so that we can authorize the latter without knowing anything about the former. I think this is a plausible analysis which may very well weaken this particular counterexample to the attitude view of consent; still, I am not convinced that the problem goes away: whether we talk of consent or authorization and even of both consent and authorization at two different levels of specificity, it seems that by consenting or authorizing the plumber to repair our boiler we have also consented to or authorized the means necessary to repair the boiler - but as we have no attitude towards any particular means but only towards the relevant end, it seems that we consent also to things towards 
which we have no attitude - so that the counterexample against the attitude view of consent still stands. ${ }^{5}$

3) So far I have only mentioned cases which I take to be perfectly rational and also reasonable given our cognitive limitations. But sometimes we just don't think: those careless people who share their private pictures with the whole wide world and are then shocked to realize that the wrong person saw the wrong picture have, in normal cases, consented to the pictures being visible to the wrong person; but they genuinely lacked the relevant attitude of approval: they did not think; it may have been stupid, it may have been silly, it may have been even reckless, but it was certainly consent - at least in most cases where there is no abuse or copyright violation.

I think that at least some versions of case (3) also represent an argument against the sufficiency of an attitude of approval for consent. Take, again, someone who carelessly uploads some pictures wanting to show them to a limited group of people A-E but ends up making these pictures available to a much larger group of people A-R. I have just argued that this person truly lacked the relevant attitude of approval towards showing the pictures to the larger group A-R but that, under certain conditions - namely the consequence was obvious, the person had been previously informed about the mechanism which would necessarily generate the consequence and had consented to it, the person may have made an inferential mistake in not realizing that $A$ implied $B$, etc. - the person may have all the same consented to the pictures being showed to the larger group A-R (even though she may have not intended that).

Now, I take it that this also shows that even though the person had an attitude of approval towards showing the pictures to the smaller group A-E, that attitude of approval is not

\footnotetext{
${ }^{5}$ Here a supporter of the attitude view of consent could try to resist the counterexample by arguing that our attitude towards the boiler working again contains all the necessary means, but that is just not true. Most people who have ever had a plumber over to repair their boiler will know that the plumber will not assume that anything goes: if the repairs are going to be particularly complicated or costly, the plumber will consult again. In short, we consent to more than we know but we don't consent to just anything. Also, let me just say that here I am not suggesting that there is no difference between consent and authorization, as there may well be a conceptual one is so far as consent is towards states of affairs rather than people and authorization is towards people rather than state of affairs.
} 
sufficient in order to identify the content of what she consents to, since the content of her consent is much wider and includes A-R. This does not mean, obviously, that the person did not consent to showing the pictures to $A-E$, but it does mean that the content of attitudes of approval is not sufficient to identify the content of what someone consents to. And, to be sure, as my positive argument in the last section will show, the reason why the person consents to A-E is not the attitude of approval towards that particular content.

4) A further case of consent without positive attitude of approval can be derived from Simmons' Chairman Jones case (Simmons 1976: 278-279): there Simmons suggested that, in the right context, silence can amount to consent. Now clearly silence does not imply an absence of the positive attitude of approval, as one explanation for the silence can obviously be that members had the relevant attitude. But just as sometimes you don't need to say 'Aye' out loud to consent, we can imagine cases in which you don't need to form or posses a psychological attitude of approval to consent. Imagine the following case: it is Saturday evening and your teenage daughter is getting ready for a night out; you aren't paying much attention as you lay on the sofa watching football, but you absentmindedly take in the chatter in the background: what she is going to wear, where she is heading to, who she is going with, etc. Your attention is never really caught by your daughter's plans and preparations and you simply have no opinion of them: but you would certainly voice your dissent in case you heard or saw the wrong things. Your lack of involvement amounts, under these circumstances, to consent. And the kind of dispositional control for which this little story is a metaphor is, it seems to be, both very widespread and a common example of how people legitimately consent to things on a daily basis without thinking or doing anything.

5) Other times we are undecided. And I think that sometimes, when we can't make up our mind, we still consent. Imagine that you are travelling with a friend: she is driving and you are on the passenger seat. There are two routes to your destination and well in advance of the point where you need to take either route1 or route2, your friend asks you which one you should take and mentions that she is happy to go with your decision. She gives you enough time and information to decide: there are differences between the two routes but those differences are not obvious or relevant enough for you to make an easy decision and 
you remain undecided. Once the bifurcation comes, you are still undecided so that your friend has to pick and picks route1. It seems to me that in this scenario it is both the case that you are genuinely undecided and also that you consented to your friend picking route1. But, and this is the crucial problem for the 'attitude' view of consent, you consented to route1 without having an attitude of approval towards route 1 because you were genuinely undecided between route1 and route2. I think that you can also describe these kinds of scenarios by saying that the subject has an attitude of approval towards both options - even though she would still lack an attitude of approval towards preferring route1 over route2; but my point here is simply that you need not describe these scenarios that way. The same goes for indifference, which can but must not be described as an attitude; indifference could also just be the absence of a negative attitude. ${ }^{6}$

This allows me to make a clarification about the attitude view: what I have here argued against is, to be precise, a psychological (or mental) attitude view. I have said that no psychological (or mental) attitude is either necessary or sufficient for consent: this still leaves room for at least two possible moves against which I have not argued here. Firstly, one could conceive of attitudes in a non-psychological way and argue that my arguments here are only directly at psychological attitudes but are silent on a non-psychological view of attitudes. Secondly, one could also argue that if the absence of certain psychological attitudes were either necessary or sufficient, that would be a kind of attitude view too. I can't discuss these other approaches in any detail here, but let me at least say here that they actually both seem to go in the direction of my own positive proposal about absence of dissent. Also, a quick point about the latter second kind of strategy: missing attitudes alone couldn't plausibly do, even though possibly omitted attitudes could; I say more about omissions in coming sections.

\footnotetext{
${ }^{6}$ Also one could here, again, suggest to distinguish between a more specific level of consent and a more general level of authorization so that the fact that we are genuinely undecided about the alternative routes does not imply that we do not have a preferential attitude towards the driver deciding for us: so that we may authorize the driver to decide for us in virtue of that preferential attitude. I think this is plausible but, again, unnecessary: we may well be also undecided about whether we prefer the driver to decide, so that we are undecided and lacking the relevant attitude both at the more specific level of consent and at the more general level of authorization.
} 
Summarizing this section, we have looked at whether consent could be a psychological attitude of approval and asked whether such an attitude would be necessary or sufficient for consent: we have argued that a psychological attitude of approval is neither necessary nor sufficient for consent, so that we will need to turn to a different view of consent. ${ }^{7}$

\section{Is Consent an Action?}

The classic alternative to the attitude view of consent is the action view of consent, according to which consent is an action. Locke, as we have seen, appeared to have something like the view that consent is an action in mind when he wrote:

I say, that every man, that hath any possessions, or enjoyment, of any part of the dominions of any government, doth thereby give his tacit consent, and is as far forth obliged to obedience to the laws of that government, during such enjoyment, as any one under it; whether this his possession be of land, to him and his heirs for ever, or a lodging only for a week; or whether it be barely travelling freely on the highway; and in effect, it reaches as far as the very being of any one within the territories of that government. (Locke, Second Treatise of Government, Sec. 119)

Here it is probably necessary to distinguish between the claim that consent is an action and the claim that actions can represent, express or imply consent - it may be argued that only the latter can be applied to Locke and that the latter does not imply the former: namely one can accept that actions can represent, express or imply consent even though one does not accept that consent is, itself, an action. I think this is a fair distinction: most people, after all, would agree that the speech act "Aye" represents, expresses, constitutes or implies consent - but that would not commit them to the view that consent is itself an action. Quite simply, the speech act "Aye" - which, we are assuming, is a genuine action - could be the expression of the relevant attitude of approval, so that supporters of the attitude view of consent can happily concede that actions can represent, express, constitute or imply consent.

\footnotetext{
${ }^{7}$ Once may view of consent has been put forward in the last section, the reader may also conclude that at least some of 1-5 are also positive arguments for my own view of consent; but here I don't mean for my view to play any role in motivating my counterexamples, and that's why I haven't yet put my view forward - I take it to be independently plausible that my counterexamples constitute consent without an attitude of approval.
} 
What is then left of the action view of consent if we accept the above distinction between consent being an action and actions representing, expressing, constituting or implying consent? Here are two further possibilities:

1) Firstly, some people may argue that some attitude is necessary but not sufficient for consent and that such attitude needs to be complemented by the relevant action which expresses or implies the attitude. Those people would then hold, contrary to our arguments in the previous section, that an attitude is necessary for consent; but they would also hold, contrary to the attitude view of consent, that some action or expression is necessary - albeit not, obviously, sufficient (given the necessity of the attitude). It is debatable whether this would be a genuine action view of consent: it would be, more precisely, an attitude/action view of consent.

2) Alternatively it may be argued that an action can be sufficient for consent independently of whether the agent possesses the relevant attitude of approval. Here there are clearly two possibilities: on the one hand, $(2 \mathrm{a})$ one may think that actions are necessary and sufficient for consent; (2b) on the other hand one may think that actions are just sufficient but not necessary - presumably because there are other ways of consenting which do not involve acting.

\section{Saunders' Action View of Consent}

Let us look at a recent argument for the view that consent is an action - where the action view of consent is applied to organ donation. Organ donation is an influential context in the debate on consent because the legitimacy of organ transplants is normally taken to depend on the donor's consent ${ }^{8}$ : for example, a very effective way of increasing the availability of organs - opt-out systems ${ }^{9}-$ is often challenged on the grounds that donors' consent is not obtained but merely presumed.

\footnotetext{
${ }^{8}$ Not always, though: Fabre (2006) is a good example of someone arguing that cadaveric organs should be confiscated independently of consent.

${ }^{9}$ To be sure: an opt-out system is one in which people sign up to opt-out of donating (and if they have not opted out their organs will be donated) whereby an opt-in system is one in which people sign up to donate (and if they have not opted in their organs will not be donated). Compare the Netherlands, which amongst the
} 
Saunders (2012) has recently suggested that this argument against opt-out systems can be resisted by appeal to the action view of consent. Saunders argues in favour of an opt-out organ donation system, on the grounds that the (on his view) problematic idea of presumed consent need not be appealed to in order to justify opt-out systems. What opt-out systems actually rely on is rather implicit consent, according to Saunders; and implicit consent, differently from presumed consent, is a genuine form of consent, at least on the assumption that some epistemic conditions are met. There are then, according to Saunders, two relevant distinctions when it comes to consenting to organ donation: the distinction between 'presumed' and 'actual' consent, and the distinction between 'implicit' and 'explicit' consent. If opt-out systems really relied on presumed consent, then we may have a problem in justifying them; but opt-out systems don't rely on presumed consent but rather on implicit consent, so the problem (with presumed consent) is avoided and opt-out systems can be justified through appeal to the overwhelming moral advantage that they would bring by increasing the availability of organs.

There are two claims at play here: on the one hand, it is argued that implicit or tacit consent is significantly different from presumed consent, to the extent that the former but not the latter constitutes genuine or actual consent. Secondly, it is argued that opt-out systems of organ donation rely on implicit consent and not on presumed consent, and that therefore we need not worry about the standard presumed consent objections to opt-out systems. The latter claim depends on the former in so far as if the former claim is false, then the latter claim is also false.

Saunders' idea is that consent is an action rather than an attitude. The action of consenting can be tacit, as when our omitting to dissent is reasonably interpreted as consenting: "For example, if the doctor says to a patient 'you need an injection - hold still' then the patient, by not withdrawing their arm or objecting, can be said to have implied their consent"

countries featured in the study is the opt-in system with the highest rate of effective consent (people that have opted in), and Sweden, which amongst the countries featured in the study is the opt-out system with the lowest rate of effective consent (people that didn't opt out): Netherlands $27.5 \%$ versus Sweden $85.9 \%$ of organ donors. Even taking the numbers most favourable to opt-in systems, then, opt-out systems make more than three times as many organs available as opt-in systems (Johnson \& Goldstein 2003: 1338-1339). 
(Saunders 2012: 71). If consent is an action rather than a mental attitude, then we can say that someone has consented only when we can identify an action of consenting; and then we cannot presume consent. Either the agent has actually (explicitly or implicitly) consented, and then we are not presuming consent because the consent has been actually given; or the agent has not actually consented, and then we ought not to presume consent because consent has not been actually given. Presumed consent is problematic, according to Saunders, exactly because consent is an action and not a mental attitude of willingness or approval.

Recognising that consent is an action allows us - according to Saunders anyway - to see the problem with presumed consent, and it also allows us to recognise that consent need not be explicit, because we often act by omitting to do something. But if consenting is an action, then we can only take it that someone has given their consent if they have intentionally consented: if the person had for example inadvertently consented or consented under duress, then that would not count as consent because the person would not have intentionally consented (this is in line with Simmons' requirements). That is why Saunders is mistaken in saying that "the action is sufficient and [the] mental attitude unnecessary... Their intentions are irrelevant to what they in fact did" (Saunders 2012: 71), at least on a reasonable interpretation of intentional action according to which the intentionality of one's actions is not independent of one's states of mind, intentions or reasons; this is a position which is accepted by pretty much everyone in the philosophy of action literature: causalists (Davidson 1980, for example) and anti-causalists (Frankfurt 1978, for example); internalists (Bratman 1987, for example) and externalists (Dancy 2000, for example). ${ }^{10}$ In a slogan, there is no actual consent without intentional consent, but then we are back at square one even if we do accept that consent is an action.

We may be willing to concede that consent is an action: but we cannot take someone to have consented to something if they have not intentionally consented to it - we have already seen Simmons making this very point independently of the action view of consent. The problem, then, is that we are back at the beginning: because, on Saunders' account, we

\footnotetext{
${ }^{10}$ For my own writings on these issues, please see Di Nucci 2008, Di Nucci 2009, Di Nucci 2010, Di Nucci 2011a, Di Nucci 2011b, Di Nucci 2012, Di Nucci 2013a, Di Nucci 2013b, and Di Nucci 2014.
} 
would no longer need to presume the action of consent, but we would still have to presume its intentionality (and this isn't a particular point about opt-out systems but a general point about implicit consent). And if the action of consent is not intentional, then the agent has not genuinely consented, as in cases of inadvertent consent or consent under duress. But then consent is still being presumed in that it is being presumed that the action of consenting was intentional. We have made no progress at all, unfortunately. This suggests that we may argue for the necessity of an action for consent but that - given the intentionality requirement - we cannot do without the attitude which makes the relevant action intentional; so that the action is not sufficient for consent but only necessary. Saunders' thesis that the action is sufficient and the attitude unnecessary fails because it does not fulfil Simmons' two requirements of intentionality and voluntariness.

In an opt-out system, the outward behaviour of two individuals may be identical, and still only one has intentionally consented to the donation of her organs. Take the following scenario: it is Sunday evening and Anna and Lena, two Austrian citizens who live in Wien, are both independently reading in the Wiener Zeitung about the recent introduction in Austria of an opt-out system for the donation of organs. The article includes a link to the government's opt-out website and even a coupon that can be cut out of the paper, filled in and sent to the relevant authorities in order to opt-out of organ donation. Anna is quickly convinced when she reads the statistics about the difference that opt-out systems make to organ availability: she decides that she will not opt out. Lena is also impressed by the statistics, but she is not sure about the system's fairness and she wants to read more about the details of the new legislation. With these thoughts in mind, they both go to bed. The next morning, while driving to work, Anna and Lena tragically die in a car crash. The outward behaviour of Anna and Lena is identical, but while Anna seems to have intentionally consented to the donation of her organs, it would be difficult to argue that Lena has. We see here that moving the debate from presumed consent to tacit consent does not help settle this case, because to determine whether Anna and Lena have tacitly consented, we must make presumptions about their states of mind in going to bed the night before they died. 
Mine is not supposed to be a counterexample to opt-out systems, as I am willing to accept that the statistical insignificance of such cases is overwhelmed by the moral emergency represented by organ shortage. The scenario only illustrates that talking about tacitly consenting as an action as opposed to talking about presumed consent does not move the debate on organ donation forward: in order to be able to adjudicate whether Anna's actions and Lena's actions implied tacit consent to organ donation, we must establish whether they intentionally consented; whether they meant for their actions to constitute tacit consent. And in order to establish that much, we must make presumptions about their states of mind, because the outward behaviour won't be enough, as the example shows. But then we are back at the beginning, we are still stuck with presumed consent; and if presumed consent is morally problematic, then we have an obstacle to the introduction of this effective solution to organ shortage.

We have shown that tacit consent as action is not significantly different from presumed consent, because in order to adjudicate whether the relevant action counts as genuine consent we still need to make some presumptions about the intentionality of the action of consenting. But, it may be objected, if consenting actions need not be explicit actions of consent (such as signing a form), but can also be other actions that imply consent, then we may be able to show that the implicating action is intentional without having to make presumptions about the implied action being intentional. Saunders offers voting as an example in which our action of voting implies consenting to the state. Could we not just say that as long as we intentionally voted, then that implies intentional consent, so that if we can show that the voting was intentional without making presumptions, then we can avoid presumed consent? In the philosophy of action, it is often said that an action can be intentional under a description while unintentional under another description, the way in which I may intentionally board the plane labelled 'London', but unintentionally board the plane for London, Ontario as I meant to fly to London, England (to take one of Davidson's (1980) famous examples). That is why even if we accept that consenting to the state is another description of voting, the intentionality of the action under the description 'voting' does not actually guarantee the intentionality of the action under the description 'consenting to the state'. 
It may be proposed, in a direction that Saunders himself mentions, that the connection between the implicating action description and the implied action description can just be normatively established by the state or some other relevant institution, thereby sidestepping citizens' awareness, not too dissimilarly from the way in which familiarity with the law is expected so that I cannot exonerate myself by telling the judge that I didn't know that what I did was illegal. There are three main problems (plus one) with this strategy:

1) If the connection between the implicating action description and the implied action description can just be normatively established by the state, then we are putting forward nothing more than a version of normative consent (which Saunders himself wants to avoid in his already cited 2012 paper, but not elsewhere (Saunders 2010)): the obligation would not be on donating organs itself, but citizens would still be duty-bound by the state's determination of what amounts to consent, including a duty to be aware of such normative determination of consent.

2) This strategy would just amount to abandoning the requirement for intentional consent, as what we would be saying is that the citizen, whether she meant to do it or not, consented because her actions implied consent and her actions implied consent because the state says as much.

3) Most of the relevant cases will not be cases of outward actions that imply consent, as with voting and consenting to the state, but rather cases of omissions that supposedly imply consent, as with Anna and Lena's omission to opt out of the Austrian organ donation system. Here the question is which of Anna and Lena's outward actions (thereby excluding Anna's mental action of deciding, as that requires presumption) will be taken to be the ones that implied consent. It may be replied that we don't need to go looking for further outward actions, as omissions are actions and therefore Anna and Lena's relevant action is their omission to opt out. 
But the problem just won't go away: how do we identify Anna and Lena's omission to opt out? If we do so by appeal to an attitude or intention against opting out, then we are back in the business of presumed consent because we are making presumptions about their attitudes and intentions. But if we can't appeal to their attitudes and intentions against opting out, how can we identify what happens as an omission to opt out? After all, every second we don't do trillions of things; and every second we don't do very many things that we could do; but not all of them will count as omissions, rather only the ones that can be somehow attributed to the agent. It has been recently proposed that we should identify omissions, as opposed to all the things that we simply do not do, not by appealing to negative intentions such as the intention to not opt out of the donor system, but rather by appealing to the absence of positive intentions (Sartorio 2009). Without going into the general value of this alternative proposal ${ }^{11}$, it is clear that this proposal won't do for present purposes because it would still rely on presumptions about what agents did not intend. ${ }^{12}$

Let us sum up: we have looked at a version of the action view of consent according to which the action is sufficient and the attitude unnecessary; this proposal promises to deal with challenges to opt-out systems of organ donations according to which opt-out systems are illegitimate because they merely presume consent. We have argued that, even if consent is an action, it must be an intentional action, but that the action view of consent cannot show that the relevant (consenting) actions are intentional without some appeal to the agent's psychological states; so that, at best, the action view of consent can show that the action is necessary, but it fails to show that the action is sufficient and the attitude unnecessary.

\footnotetext{
${ }^{11}$ I see at least a further problem: that an agent did not intend to opt-out isn't enough, we need the agent to have omitted to intend to opt out, just as earlier we needed the agent to 'Omit to Opt-Out' rather than just 'Not Opting Out' - but this will generate a vicious regress.

12 I mention the fourth problem only in footnote because it is only relevant to the case of organ donation: 4) There is a further problem with the idea that the significance of the citizen's actions be determined by the state. The suggestion appears to be that it is a duty of every citizen to deliberate on the question of organ donation, so that the actions of those who omitted to fulfil their duty by failing to deliberate on organ donation will still be interpreted by the state as implying tacit consent to organ donation - on the ground that the citizen should have thought about it. Would it be unreasonable for someone to argue that they may not want to deliberate on the topic? There are clearly overwhelming moral reasons to worry about the issue of organ donation, but are they enough to bound every citizen to think about it? It may be suggested, for example, that a person's relationship with her death is private, so that the state cannot force someone to think about such a private issue.
} 
Two of the three options open to the action view of consent have then be shown to be problematic: the claim that the action is necessary and sufficient and the claim that the action is sufficient. The only option left would not even be a true version of the action view of consent: the attitude/action view of consent according to which both attitude and action are necessary for consent. But we have already shown in section 2 what the problem with this view is, namely that the relevant attitude is not necessary. All we are left with, then, is merely the claim that some action is necessary for consent. In the next and last section I shall argue against the necessity of action for consent and sketch an alternative view of consent according to which all there is to consent is absence of dissent (under legitimate epistemic conditions).

\section{Absence of Dissent}

In order to consent, we don't need to act. This is the claim that I shall defend in this final section, thereby rejecting even the weakest version of the action view of consent according to which action is necessary for consent. According to my own view of consent, the absence of dissent is, under legitimate epistemic conditions, enough. ${ }^{13}$

Of its own, the claim that action is unnecessary may be deployed by supporters of the attitude view of consent too. Take the already mentioned case of someone who is delivered unconscious and in critical condition to the emergency rooms: supporters of the attitude view of consent may here claim that the unconscious patient has the relevant attitude even though she cannot express it; since the relevant attitude is sufficient and the action unnecessary, then here supporters of the attitude view of consent can explain why surgery is legitimized by the patient's consent even though the patient is unconscious.

Given that we have already argued against the attitude view of consent, this option is not open to us: if we are going to argue against the necessity of action, we can't fall back on the sufficiency of the attitude - indeed, given our previous arguments we can't even fall back on the necessity of the attitude. Therefore, once we deny the necessity of the action there is, to

\footnotetext{
${ }^{13}$ Douglas \& Douglas (2009) have also talked about absence of dissent in the context of organ donation.
} 
be honest, nothing left. Neither attitude nor action is either necessary or sufficient. That is why we need to appeal to something else: the absence of dissent.

First of all, let me say that the view that action is unnecessary for consent isn't new: indeed, it is as old as consent itself, at least if we start with Locke: "the very being of any one within the territories of that government" (Locke, Second Treatise of Government, Sec. 119). That is neither an action nor an event: it is, at best, a state of affairs; and it isn't even a state of affairs of which we can say that it has been generated, necessarily, by the subject's actions birth seems to be the obvious case here, where we can, at best, appeal to someone else's actions.

The fact that Locke appears to have rejected even the weakest version of the action view of consent does not necessarily imply that on Locke's account, or any other account based on Locke, agency does not play any role in consent: indeed, agency may turn out to be crucial even though the account does not need to identify any of the agent's actions as being necessary for consent. The crucial role of agency may simply be that the plausibility of someone consenting to the laws of the land just by being within that land's territories may depend on that agent's capacity for agency. Namely, if she weren't an agent then we couldn't argue that her mere being within the country's territory constitutes consenting to its laws: so that someone can act may be necessary for consent even though no particular action is necessary in order for someone to consent.

Another way of saying this is to claim that as long as the agent could have dissented - as long as dissent was accessible to her - then no action of consenting or action which expresses or implies consent is necessary: the absence of dissent is sufficient. The crucial condition, then, is a person's access to dissent - so I shall now explain what I mean by that, starting by saying that I understand dissent to be an intentional action.

Let us look at the already discussed case study of opt-out systems of organ donation: the point about access to dissent is meant to guarantee legitimate epistemic conditions in the 
agent's environment. ${ }^{14}$ This is not just a question of guaranteeing voluntariness as required by Simmons, so that for example if someone's opt-out form has been hidden from her, then her environment is not epistemically legitimate and she cannot be said to have voluntarily omitted to opt-out. In line with Simmons' other requirement - intentionality - the issue is also that there must be access to the relevant information: the agent, for example, must not be an analphabet; the state or health service (or whichever the relevant institution is) must have made a reasonable effort to inform the agent; a reasonable period of time must have passed since the relevant change in legislation and also since the relevant institution's effort to inform (these examples are not supposed to exhaust the requirements but rather only to be representative of the kinds of requirements that I envisage: agential requirements, institutional/environmental requirements, and temporal requirements) ${ }^{15}$. Again, without such epistemic access then we cannot say that the agent intentionally omitted to opt-out. In those cases we may say that agents didn't consent because they had no access to dissent.

Three clarifications: (1) firstly, my view does not appeal to the agent's attitudes or psychological states in order to establish whether or not the agent intentionally omitted to dissent or whether she merely did not dissent. Given access to dissent as we have just defined it, that the agent did not dissent qualifies as intentionally omitting to dissent. In other words:

$\underline{\text { access to dissent }}+\underline{\text { did not dissent }}=\underline{\text { intentionally omitted to dissent }}=\underline{\text { consented }} .{ }^{16}$

In this respect, my view is closer to Sartorio's already mentioned account of omissions at least as far as there is no appeal to positive psychological states. On the other hand my view

\footnotetext{
${ }^{14}$ I am happy to admit that, once this account of consent is applied to the many different relevant fields, it may turn out that access to dissent is also an epistemic matter but not only an epistemic matter, so that some of the conditions which limit or deny access to dissent are not purely epistemic conditions - so that fear or poverty certainly limit epistemic access but may limit access to consent in ways that are not only epistemic ones. Just one example: the unwilling bride may know all the relevant facts and still not consent even though she says "Yes" because her access to dissent is limited or denied through violence.

${ }^{15}$ Once we exit the current case of organ donation, institutional requirements would more generally amount to agent-independent requirements to do with other agents and the environment.

${ }^{16}$ Here I am just stipulating what it means to 'intentionally omit for present purposes, but I accept that it may be legitimate to also talk of 'intentional omissions' in other cases which would not qualify as 'intentional omissions' in my current sense because they would fail to meet the conditions for access to dissent: cases of coercion, for example, do not need to be necessarily classified as unintentional.
} 
is different from Sartorio's because psychological states are not mentioned at all in my view, only access to dissent is (recall that Sartorio's view does not appeal to a positive intention to not $A$ but still appeals to not intending to $A)$.

(2) Second clarification: in not mentioning the agent's attitudes at all but only the epistemic environment, my view, in some sense, makes consent out to be independent from a person's preferences. This is, on the face of it, strange: isn't the whole requirement of consent exactly meant to guarantee that personal preferences are not disrespected?

Respecting personal preferences in the relevant moral domains is certainly paramount, and I think that my view can do that and some: by focusing on not dissenting my view identifies a crucial aspect of personal preferences, one that I think is possibly even more important than their quality: the weight of preferences. The fact that, given epistemic access, someone has not dissented tells us not only what her preferences were but also how much weight those preferences had for that person: in this case, enough weight so that she would not dissent or not enough weight for her to dissent. This focus has some crucial advantages over approaches that only look at the quality and direction of preferences: it does not rely on introspection or personal reports, for example.

(3) Let us go back to the example involving Anna and Lena to explain another feature of my "no dissent" view which I take to be an advantage over other accounts of consent: according to my view, if the epistemic context in the scenario involving Anna and Lena is not legitimate, we cannot talk of consent notwithstanding the subjective preferences of those involved. Namely, access to dissent is not only sufficient but also necessary for consent on my view: this explains why Lena has not consented to organ donation in the scenario - she hasn't had enough time and information to make an informed decision on the issue. It is also a consequence of my view that Anna hasn't consented either even though she is in favour of donating and has consciously formed such attitude the night before; this, it may be argued, is a counterintuitive upshot of my view. Whether or not it is counterintuitive, I think that it is a good upshot of my view: if the change in legislation had been reported only the day before, it is plausible to assume that people hadn't had enough time to make an informed 
decision on the issue, independently of what their subjective preferences were: at least institutional and temporal requirements have, in our scenario, not been satisfied.

This is an important point: it shows that the "no dissent" view of consent is not offering a watered-down version of consent where almost everything goes: on the contrary, it is a robust account that goes a long way to satisfy the requirements of informed consent exactly because it insists on epistemic access.

In conclusion, I would like to mention one more advantage of my "no dissent" view of consent: epistemic access can easily be thought to be context-dependent, so that the criteria for what will or will not qualify as epistemically accessible can vary from context to context in the tradition of contextualism in epistemology. This is not the place to defend the latter, so I will just briefly say why this possibility is particularly well-suited when talking about consent: as we have already mentioned, there are at least two very different streams in the philosophical literature on consent (and many others in between). On the one hand, there is consent in bioethics and medical ethics: here we have seen and discussed the example of organ donation. On the other hand and independently from discussions of consent in bioethics and medical ethics there is the debate on the role of consent in justifying political obligation: here we have seen and discussed the classics Hobbes and Locke and Simmons' influential modern critique.

Those two traditions do not normally feature in the same articles, books or discussions (a rare exception is the already cited Miller \& Wertheimer 2010); here I shall not comment on the dialectic of this continuing divide but just say that if one endorses the "no dissent" view of consent based on epistemic access one may be able to do justice to both the similarities and differences between the discussions of consent in medical ethics and the discussions of consent in political obligation (and what's in between those two poles too): it may be, say, that the criteria for what qualifies as consent to the laws of the land are much weaker than the criteria for consent to serious medical procedures. This may explain, historically, why those two debates have been running separately from each other while using the same word, 'consent'. But I do not think that this continuing separation is necessary: if we endorse 
the "no dissent" view of consent, we may be able to discuss both issues by appealing to the same concept of consent while at the same time recognising that its conditions for what qualifies as epistemic access differ from context to context. ${ }^{17}$

\section{References}

Beyleveld D. \& Brownsword R. 2007. Consent in the Law. Oxford: Hart.

Bratman M. 1987. Intention, Plans, and Practical Reason. Harvard UP.

Dancy J. 2000. Practical Reality. Oxford UP.

Davidson D. 1980. Essays on Actions and Events. Oxford UP.

Di Nucci E. 2008. Mind Out of Action. VDM Verlag.

Di Nucci E. 2009. Simply, false. Analysis 69 (1): 69-78.

Di Nucci E. 2010. Rational constraints and the Simple View. Analysis 70 (3): 481-486.

Di Nucci E. 2011a. Automatic Actions: Challenging Causalism. Rationality Markets and Morals 2 (1): 179-200.

Di Nucci E. 2011b. Frankfurt versus Frankfurt: a new anti-causalist dawn. Philosophical Explorations 14 (1): 117-131.

Di Nucci E. 2012. Priming Effects and Free Will. International Journal of Philosophical Studies 20 (5): 725-734.

Di Nucci E. 2013a. Action, Deviance, and Guidance. Abstracta 7 (2): 41-59.

Di Nucci E. 2013b. Mindlessness. Cambridge Scholars.

Di Nucci E. 2014. Ethics Without Intention. Bloomsbury.

Douglas TM \& Douglas NM. 2009. Absence of significant dissent should be sufficient for deceased donor organ procurement in New Zealand. Aust N Z J Public Health 33(5):449-54.

Fabre C. 2006. Whose Body Is It Anyway? Oxford UP.

Frankfurt H. 1978. The Problem of Action. American Philosophical Quarterly 15: 157-162.

Hobbes T. 1651. Leviathan.

Johnson EJ \& Goldstein D. 2003. Do Defaults Save Lives? Science 302:1338-1339.

Locke J. 1689. Second Treatise of Government.

\footnotetext{
${ }^{17}$ I would like to thank Kristin Voigt and Marcel Heusinger for comments on previous drafts of this article; also, I would like to thank audiences in Stirling, Eindhoven, Ghent, Köln, Konstanz, and Essen for useful comments on this material.
} 
Miller FG \& Wertheimer A. 2010. Preface to a theory of consent transactions: beyond valid consent. In The Ethics of Consent, edited by F. G. Miller and A. Wertheimer. New York:

Oxford University Press.

O’Neill O. 2003. Some limits of informed consent. Journal of Medical Ethics 29(5): 4-7.

Sartorio C. 2009. Omissions and Causalism. Noûs 43:513-530.

Saunders B. 2010. Normative consent and opt-out organ donation. J Med Ethics 36:84-87.

Saunders B. 2012. Opt-out organ donation without presumptions. J Med Ethics 38:69-72.

Simmons AJ. 1976. Tacit Consent and Political Obligation. Philosophy \& Public Affairs 5(3):

274-291. 